\title{
Sector stability criteria for a nonlinear axial motion string system
}

\author{
Rui $\mathrm{Wu}^{1}$, Yi Cheng ${ }^{2}$, and Donal O'Regan ${ }^{3}$ \\ ${ }^{1}$ Changchun University of Finance and Economics \\ ${ }^{2}$ Bohai University \\ ${ }^{3}$ National University of Ireland
}

April 26, 2021

\begin{abstract}
The paper investigates the exponential stability criterion for an axially moving string system driven by a nonlinear partial differential equation with nonlinear boundary feedback. The control criterion based on a sector condition contains a large class of nonlinearities, which is a negative feedback of the velocity at the right boundary of the moving string. By invoking nonlinear semigroup theory, the well-posedness result of the closed-loop system is verified under the sector criteria. Furthermore, a novel energy like function is constructed to establish the exponential stability of the closed-loop system by using a integral-type multiplier method and the generalized Gronwall-type integral inequality.
\end{abstract}

\section{Hosted file}

WU.pdf available at https://authorea.com/users/410105/articles/519598-sector-stabilitycriteria-for-a-nonlinear-axial-motion-string-system 